\title{
Futebol dos futebóis: dissolvendo valências simbólicas de gênero e sexualidade por dentro do futebol
}

\author{
Football of the footballs: dissolving symbolic valences of \\ gender and sexuality inside the football
}

\author{
Luiz Henrique Toledo \\ Universidade Federal de São Carlos (UFSCAR), São Carlos/Brasil \\ Doutor em Antropologia, USP \\ kikeppgas@gmail.com \\ Wagner Xavier Camargo \\ Universidade Federal de São Carlos (UFSCAR), São Carlos/Brasil \\ Doutor em Ciências Humanas, UFSC
}

\begin{abstract}
RESUMO: O futebol, entre inúmeras práticas lúdicas historicamente esportivizadas, manteve-se hegemônico a partir de múltiplas projeções e experiências valorativas, políticas, estéticas e sensoriais, tornando-se paulatinamente uma espécie de "índice canônico" para se pensar, de modo geral, formas de sociabilidade na contemporaneidade. Em seus desdobramentos simbólicos, ele não apenas se expandiu territorialmente, como tem oferecido um conjunto de metáforas aos "modos de existência" de indivíduos e grupos. Partindo desta ideia de senso comum sobre dada "hegemonia" do futebol, mas partilhada academicamente, propomos perceber que tais "modos" se materializam e se disseminam em "múltiplos futebóis" que alcançaram expressões politizadas e que podem ser explorados "de dentro" deste fenômeno global. Para tanto, trazemos um caso ocorrido durante a Copa do Mundo da Rússia-2018 e refletimos sobre a sexualização de corpos no contexto futebolístico midiatizado, pensando o futebol pela relativização de seus modos simbólicos de impor suas regras e sociabilidade esportivas, tomadas tacitamente como universais.
\end{abstract}

Palavras-Chave: Antropologia das práticas esportivas, Futebol; Hegemonia; Copa da Rússia; Sexualização de corpos.

ABSTRACT: Among uncountable playful practices historically sportivized, football has remained hegemonic because of multiple projections and valuable, political, aesthetic and sensorial experiences, gradually becoming a kind of "canonical index" used to think generally over forms of sociability in the contemporary society. In its symbolic unfolding, football has not only expanded territorially, but it offered a set of metaphors to the "ways of life" to individuals and groups. Starting from this notion of hegemony, which is shared academically among peers about the hegemony of football as a phenomenon, we propose to realize that these "ways" can materialize and be disseminated in "multiple footballs", which have reached politicized expressions and can be explored from the "inside" of this global phenomenon. To do so, we bring to light a case which has occurred during the 2018 World Cup in Russia and reflect on the sexualization of bodies in the mediated football context, rethinking the phenomenon by relativizing its symbolic ways of imposing its sporting rules and sociability, taken tacitly as universal.

KEYWORDS: Anthropology of sporting practices; Football; Hegemony; Russian World Cup; Sexualization of Bodies. 


\section{MAPEANDO FUTEBóIS NO FUTEBoL ${ }^{1}$}

Sabe-se que o futebol, entre incontáveis práticas lúdicas historicamente esportivizadas, manteve-se hegemônico a partir de múltiplas projeções e experiências valorativas, políticas, sensoriais e estéticas, tornando-se paulatinamente uma espécie de "índice canônico" para se pensar, de modo geral, formas de sociabilidade em contextos urbanos. Dos passatempos privados e experimentais aos campeonatos profissionais regrados e legislados segundo princípios de uma racionalidade estatal, passando pela considerável presença midiática corporativa, impôs-se não somente por suas técnicas corporais apreendidas desde tenra infância (consideravelmente estimuladas nos círculos mais próximos de parentesco e amizade a imprimir continuamente suas grades classificatórias clubísticas às crianças e aos jovens), como também acabou por expandir seu vocabulário metafórico como forma de apreensão de outros domínios historicamente contíguos, ${ }^{2}$ tais como a política, a economia, esportivizando até mesmo domínios como a religião ${ }^{3}$ ou grupos étnicos historicamente mais refratários aos modos de vida ocidental, como se nota em paisagens indígenas. ${ }^{4}$

Impondo fortemente sua linguagem franca à vida cotidiana, tornou-se um fenômeno aderente aos inúmeros valores que ordenam todo um simbolismo de poderes constituídos. 0 futebol em seus desdobramentos simbólicos na e para a vida expressou e expandiu não somente territórios físicos (alcançando como prática política e esportiva centenas de nações), mas também territórios existenciais supostamente seguros, alicerçados em modos de vida marcados em princípio pelo seu eurocentrismo, porém apropriados como índice identitário em muitos outros domínios a ponto de produzir nacionalismos esportivos em outros continentes (América do Sul e África) ou tornando-se um esporte potencialmente nacionalizável, tal como se observa mais atualmente em regiões como a China e Oriente Médio. Queremos salientar, então, que as dissoluções de sua hegemonia

\footnotetext{
${ }^{1}$ Este artigo é oriundo de discussões sistemáticas realizadas pelo grupo de antropologia das práticas esportivas, dentro do Laboratório de Estudos das Práticas Lúdicas e de Sociabilidade (LELUS), na UFSCar.

2 ELIAS. A busca da excitação, 1992.

${ }^{3}$ OLÉCIO. A sociabilidade esportiva das igrejas Renascer em Cristo e Bola de Neve, 2009.

${ }^{4}$ COSTA. Inkidene Hekugu. Uma etnografia da luta e dos lutadores no Alto Xingu, 2013.
} 
em formas identitaristas, as quais prenunciam muitos futebóis praticados contemporaneamente, ${ }^{5}$ desde que tomados de um ponto de vista algo externalista, caminham pari passu com tradicionais estratégias expansionistas em outras paisagens, dando mostras de seu vigor institucional, e por que não dizer politicamente conservador, que o mantém numa chave ideológica, mas também em boa medida epistêmica, como "esporte global".

Até bem pouco tempo e para além de seu conhecido expansionismo imperialista, seus territórios existenciais sobrepuseram-se às fronteiras mais aderentes aos valores políticos de Estado, naturalizando expressões analógicas e modos de vida calcados em posições binárias atinentes à natureza do próprio jogo, tais como vitória e derrota, meritocracia e desempenho, sucesso e fracasso, identidade e dissonância, paz e guerra, economia e subsistência, enfim, valores pensados dentro de uma ampla matriz referencial que, a partir de releituras em vários domínios do conhecimento já há algumas décadas (na filosofia, antropologia, sociologia, nos estudos culturais e mesmo nos estudos de gênero), poderia ser indexada como sendo expressão multipolar de valores masculinos, que ordenaram historicamente os sistemas simbólicos no Ocidente e para além dele. Ou, para sermos mais diretos, sabe-se hoje que o futebol e muitos dos esportes correlatos recalcaram o binarismo ou dimorfismo biológico entre sexos que, por muito tempo, norteou as experiências hierárquicas (portanto políticas), entre gêneros, dentro e fora do esporte.

Portanto, quase como um símbolo que se representa a si mesmo, ${ }^{6}$ o futebol diz muito do que se pensa que se sabe sobre ele na exata medida em que se projetam extensões de subjetividades masculinas hegemônicas, acolhidas nos manejos do jogo, no seu linguajar e gestualidades, nos modos de ser observados no convívio entre torcedores, no contato físico imposto por suas regras e técnicas da perspectiva de quem o pratica no sentido de buscar a mimese competitiva, nas relações promíscuas que desde sempre estabeleceu com as esferas de poder, locus das hierarquias de gênero. ${ }^{7}$ Por isso há quase sempre uma comparação tácita,

\footnotetext{
${ }^{5}$ CAMARGO. A Champions LiGay e a colonização do futebol, 2018.

${ }_{7}^{6}$ WAGNER. Símbolos que representam a si mesmos, 2017.

7 Não é muito comum encontrarmos na literatura acadêmica brasileira atual trabalhos que problematizam questões de gênero relacionadas ao universo da política representativa. Nesse
} 
implícita ou explícita, entre este futebol e alguma expressão dele derivada. Essas aparentes contiguidades, não problematizadas entre experiências que aproximam o futebol de outros ambientes, podem sugerir que as dissonâncias em torno desse esporte possam ter nascidas somente a partir de "um fora", de uma crítica externalista que finalmente o alcançou, ainda que tardiamente, deslocando-o de sua “zona de conforto" como esporte hegemônico e masculinizante.

Neste ensaio, no entanto, trazemos um caso ocorrido no epicentro do futebol hegemônico, qual seja, a Copa do Mundo de Futebol masculino, na edição sediada na Rússia em 2018, para pensar não apenas o que pode ser mobilizado por torcedores/as nestes eventos no âmbito da fruição esportiva misógina que historicamente apareceu como um dado não problemático (expresso nas piadas preconceituosas, xingamentos jocosos, violência física como afirmação de masculinidades, sexualização de corpos), mas inverter um pouco todo um movimento argumentativo que hoje está presente em relação a visibilidade de tantos outros futebóis dissonantes, que se fazem presentes numa paisagem sensivelmente diversa e crítica em relação aos binarismos impostos pelo seu caráter competitivo e profissional.

Ou seja, nosso intento será perceber que tais dissonâncias, hoje tão visibilizadas a partir de várias viradas ontológicas que alcançaram expressões muito politizadas, podem ser exploradas desde "de dentro" deste fenômeno global (tão naturalizado em seus valores) que é o futebol. É como se pudéssemos dizer que o futebol que quase sempre se apresentou hegemônico e portador de identidades monolíticas relacionadas geralmente à noção de Estado-Nação, ao menos nas suas características mais decisivas, também pode ser desconcebido a partir dos mil futebóis dissonantes, que mais ou menos silenciosamente o integralizaram.

Portanto nossa provocação será no sentido de compreender as valências simbólicas singulares que sempre estiveram ali e que hoje impõem "mil" futebóis de feições identitaristas, expressas a partir dele nas tomadas de posições políticas

sentido, destacamos a pesquisa de Bruna Potechi (2018), que em tese de doutorado, intitulada Fazer mulher, fazer lei, aponta para um feixe de feminilidades e ações generificadas que tentam mudar a força de gravidade das disputas do jogo parlamentar, fortemente marcado pelas práticas da misoginia. 
de novos sujeitos na esfera pública, tais como a presença dos torcedores antifascistas pelo mundo afora ou a presença de times amadores que têm politizado a prática esportiva e feito a crítica ao futebol estatal e de espetáculo, ou ainda práticas generificadas que têm se empenhado na dissolução existencial do futebol mercadológico e misógino. É a partir do próprio futebol hegemônico, que ao tentar manter seu status quo pelos torneios e megaeventos intercontinentais e na sua imensa capilaridade em espetáculos locais, que se pode fazer transbordar formas dissonantes em práticas que permanentemente o tensionam.

Se hoje muitas dessas práticas dissonantes vem à público e se tornam visíveis até mesmo nas mídias mais conservadoras é porque também já estavam pressupostas como motes insurgentes, embora pouco visibilizadas, ou ainda pouco suscetíveis de serem problematizadas pelos observadores/as e pesquisadores/as, que igualmente comungavam da naturalização e singularização da sua masculinidade como espécie de propriedade hegemônica não problemática.

Apenas para exemplificarmos esse movimento que se insinua "de dentro" do campo aparentemente hegemônico podemos destacar da bibliografia mais consolidada e diríamos "tradicional" sobre futebol nas Ciências Sociais um autor que, por muito tempo, se posicionou quase que de maneira solitária em relação aos estudos de gênero, ou de algum gênero, na interface com os esportes. Pluralizando os fenômenos esportivos como expressões de masculinidades ao focar a problemática da identidade argentina, este autor pode ser considerado um teórico que antecipou o uso de toda uma literatura que hoje está mais disponível aos pesquisadores brasileiros sobre esportes, tais como, por exemplo, as pesquisas etnográficas de autoras feministas como Marilyn Strathern. ${ }^{8}$ Portanto, Masculinidades (2003) pode ser considerada uma obra de referência que contrasta com os estudos que lidaram com as identidades nos esportes de modo não problemático da perspectiva de gênero.

Queremos dizer com isso que o problema da multiplicidade ou das perspectivas de apropriação dos futebóis dentro do Futebol sempre foi inerente à sua prática, quer profissional e espetacular, quer lúdica, e visibilizar as pequenas ou mil insurgências em seu interior é perceber um movimento de dentro, que hoje

${ }^{8}$ ARCHETTI. Masculinidades, 2003. 
se projeta com intensidade também a partir de novos atores que reivindicam a prática como índice de empoderamento de novas identidades no e do esporte.

\section{A SEXUALIZAÇÃO DE CORPOS E DISCURSOS ESTEREOTIPADOS NO FUTEBOL}

No dia do primeiro jogo da seleção brasileira, na Copa do Mundo de Futebol masculino na Rússia, um grupo de turistas brasileiros convidou uma garota russa para confraternizar com eles a torcida pelo Brasil. Dos gritos de "Brasil", "Brasil", logo iniciaram em coro outra expressão, para eles entre engraçada e irônica, que idolatrava o que se chamou de "boceta rosa". Entre risos sarcásticos e pulos efusivos, os machos-alfa continuaram a pronunciar tal frase incitando que a garotatorcedora a repetisse. Em tempos de fibra ótica e internet ultraveloz, o episódio gravado caiu nas redes sociais e ganhou o mundo. ${ }^{9}$

Ultrajante, porém longe de ser inédita, a conduta destes profissionais liberais (ao menos um deles identificado como sendo engenheiro) e agentes do estado (funcionário público, polícia militar) impuseram a dinâmica da humilhação à jovem russa induzida na armadilha do "congraçamento entre povos", de resto algo propalado pelo modelo exclusivista, elitista e misógino do padrão FIFA em Copas do Mundo.

A repercussão foi ampla e virulenta nas redes sociais e mesmo na TV, tanto no Brasil, quanto no exterior; houve chacota sobre os atos, mas principalmente condenação coletiva dos mesmos, considerados aviltantes. Se outrora passariam incólumes, inclusive para suas próprias mães e irmãs, desta vez não foi bem assim. Em tempos de recrudescimento de ânimos e de "guerras sexuais" (como as travadas entre grupos não-heteronormativos e religiosos), a "ingênua brincadeira" foi, inclusive, alvo de representação jurídica contra esses indivíduos. ${ }^{10}$

\footnotetext{
${ }^{9}$ Conforme se vê, particularmente, em: "Vídeos machistas de torcedores na Rússia se espalham pela web e causam revolta" <https://glo.bo/2WloTbb>.

${ }^{10}$ Seriam essas "guerras sexuais" da atualidade novas roupagens para velhas temáticas que povoaram os anos mais engajados das ondas feministas? A resposta é afirmativa se tomarmos que: "Discussões sobre a política da sexualidade começaram na primeira onda feminista e ainda não terminaram" (tradução livre). DUGGAN; HUNTER. Contextualizing the Sexuality Debate, p. 15.
} 
A dinâmica da festa em solo estrangeiro longínquo está longe de ser popular, daí o conjunto de fãs pelo selecionado abrigar, em sua ampla maioria, torcedores de alguma posse, identificados como brancos de classe média a realizar o sonho de ver uma Copa do Mundo. Em realidade, os "bons moços", incorporando o modelo do breadwinner (a figura do trabalhador e bom marido, branco e heterossexual, propagada pós-Segunda Guerra Mundial) ao entrarem como turistas na Rússia de Putin, tornam-se bad guys ou verdadeiros "predadores sexuais" frente ao que consideram o exótico, o inalcançável, que seria a mulher russa, loira e de beleza padrão, sexualizada e fetichizada.

A quebra das regras da sociabilidade fora dos círculos familiares, do trabalho, do cotidiano explicitada por esses sujeitos, a distância do próprio país, o suposto anonimato que o deslocamento territorial lhes confere, enfim, carregam alguma excitação novidadeira que nutriu as desculpas e justificativas da parte dos envolvidos, que trataram o assunto como se fosse algo justificável e levemente condenável. Mas há nessas justificativas, um tanto infames, uma profunda despolitização de seus corpos, dos corpos de suas vítimas, dos corpos torcedores, ademais, despolitização da Copa como locus de embates figurados entre nações, grupos étnicos, bem como enfrentamento das subjetividades.

Do ponto de vista desses torcedores e de tantos outros que os seguiram nas redes sociais se indignando ou minimizando o ocorrido, a tese é que foram vítimas da excepcionalidade que acomete todos os "homens de bem" (ironicamente falando), ciosos da moralidade normativa ou heteronormativa. Aqui é interessante perceber que, dentro do campo esportivo, equivocadamente julgado apartado da sociedade como um todo, os corpos aparecem como marionetes dentro do palco da heteronormatividade, por meio da qual a heterossexualidade é tida como pressuposto obrigatório. ${ }^{11} \mathrm{E}$, o mais grave é que nesse campo as normatividades estão postas nos discursos, do sexo ao gênero, da biologia à cultura, em corpos praticantes e observantes.

Assim, os brasileiros-torcedores, apanhados numa espécie de arapuca onde figuram corpos, cheiros e fenótipos exóticos inebriantes (afinal, "bocetinhas rosas" de jovens russas não figuram o tempo todo e à disposição desses sujeitos), foram

\footnotetext{
${ }^{11} \mathrm{RICH}$. La heterosexualidad obligatoria y la existencia lesbiana, 1999.
} 
flagrados numa conjuminação entre a experimentação hipotética de um sexo exótico e a constatação de uma sexualidade já deixada para trás e recalcada pela seriedade da vida (adulta, profissional). Tais torcedores, a partir disso, ingressam numa espécie de regressão psíquica, passageira e supostamente inocente, passível de perdão, justamente porque abrigada tanto no inconsciente capcioso quanto nos corpos desejantes reprimidos. Portanto, pouco ou nada teria o caso a ver com o domínio político de gestão da pessoa, sobretudo no trato com outras, das posses e vontades conscientes.

Porém, é preciso lembrar que ao menos desde a Copa passada, realizada no Brasil em 2014, já houvera relatos de torcedores brasileiros, presentes nas festividades pós-jogos no bairro da Vila Madalena em São Paulo, que igualmente expuseram estrangeiros a semelhantes "pegadinhas" em nome da jocosidade acobertada pela recíproca da ignorância entre idiomas. Torcedores orientais, igualmente jovens e sorridentes, repetiram exaustivamente a expressão "eu sou veado", "quero dar o cu", que pipocaram aqui e ali sem a repercussão que o caso da jovem russa alcançou, agora quatro anos depois. E desses xingamentos outra dimensão se desvela: a da homossexualidade como inferior à heterossexualidade e, mais grave ainda, o pressuposto preconceituoso e equivocado assentado na afirmação de que o sexo anal é algo reprovável e descabido.

De positivo acerca do fato ocorrido com a jovem russa e os torcedores brasileiros fica (talvez) como lição a propagação veloz (viralização) das incontáveis vozes indignadas nas redes sociais. De negativo, certamente, o avanço apenas relativo e restrito da crítica, uma vez que a repercussão da famigerada "pegadinha" se manteve segura dentro do ambiente heteronormativo da cultura misógina, não se eximindo da interpretação conservadora, tais como aquela que ainda concebe o episódio como mais um confronto entre homens "abutres" e uma "indefesa" e jovem mulher. Inclusive parece que é dentro dessa chave escamoteadora que a desculpa dos homens também se orientou, ou seja, reconhecendo o mau gosto da "piada", porém, mantendo intocáveis as raízes da própria misoginia. Aqui não estamos tão distantes dessas lógicas paroxistas em que se formam breves consensos coletivos expiatórios, nos quais participantes tomados individualmente se isentam, culpabilizando o coletivo precário, e o mau feito passaria a ser 
sublimado em representações que se autonomizariam de seus agentes e ações concretas. Tudo se desloca, se quer crer, para o plano das representações facilmente conversíveis em tomadas de consciência.

Outros casos nessa mesma Copa da Rússia espocaram e vieram à tona, tendo como vítimas crianças ou adolescentes e o efeito da hierarquia moralizante (porém, sempre conservadora) se repetiu, ou seja, "não se faz isso com a inocência". Foi possível ainda ler nos comentários de internautas em fóruns de discussão nas redes sociais, que ninguém faria isso com homens fortes, mais musculosos ou masculinizados, porque seriam passíveis de uma retaliação física.

Mas todos esses fatos estão longe, porque também muito próximos, de ocorrerem tão somente em função da aparente (e não menos preconceituosa) vulnerabilidade das vítimas, sobretudo porque repousam intocadas estruturas narrativas sobre a sexualidade, que merecem alguma atenção. Voltaremos a elas logo adiante.

Ao menos dois casos aproximados e já muito explorados se destacaram na Copa realizada no Brasil: o famoso "Dilma, vai tomar no cu", desferido pelo coro das frações de classe endinheirada, confinadas nas arquibancadas do estádio corintiano, por ocasião da abertura da Copa, e o "puto", xingamento expressado pelos torcedores mexicanos na reposição da bola pelo goleiro adversário, que rapidamente se transformou num hit (ohhhhhhhh bichaaaaaaa!),12 ecoado pelas arquibancadas brasileiras já há quatro anos. A FIFA ameaçou, mais uma vez agora, assim como tentara antes mas sem resultados, punir semelhante má conduta torcedora coletiva em relação aos cantos e gritos que explicitam preconceito; afinal, seria ela a legislar sobre a sociabilidade dentro dos estádios! Porém, silenciou-se até o momento em relação a casos como o da jovem russa, talvez porque o fato não tenha ocorrido dentro dos limites territoriais de suas higienizantes fanfests.

De todo modo, predominou um silêncio condenável acerca do caso em questão da torcedora russa, talvez porque haja outros fatos que se desdobram de uma Copa e hierarquizam pautas jornalísticas, ou pelo fato de que isso participa de uma dada "sociabilidade torcedora" (masculina), que a FIFA patrocina e

\footnotetext{
${ }^{12}$ Desdobramentos desse episódio podem ser lidos em Toledo, 2014.
} 
amplamente valida, e que, no limite, não interessa ser problematizada, mesmo porque é dada como expressão pontual, localizada e subsumida ao fervor torcedor durante os dias do evento.

Se a FIFA conseguiu afastar os torcedores reconhecidamente mais violentos dessa Copa, muito por conta da política de encargos imposta aos países que se submetem a realização desses megaeventos (excluindo ou minimizando a presença de torcedores hooligans), não se deve desconsiderar que muito da sociabilidade popular também acabou higienizada dentro desse processo - tanto na Rússia, quanto no Brasil.

Não devemos desconsiderar totalmente o fato de que a misoginia à brasileira, protagonizada tanto em terras brasileiras quanto russas, pode ter sim uma proximidade (ou ao menos um apelo indutor) a valores arraigados de classe, apregoados na elitização do espetáculo promovido pela FIFA. Até a suposição (de parte dos homens) de que estariam impunes e o espanto ou surpresa anunciados na justificativa de que se tratava apenas de "brincadeirinhas de mau gosto", colocam sob suspeita toda a ambientação promovida e patrocinada pela FIFA.

Os discursos políticos da FIFA cumprem uma agenda mais conservadora ao tomar a identidade associada a outras noções correlatas, por exemplo, território, soberania nacional, ou noções culturalistas essencializadas e associadas à noção de cultura como um todo homogêneo funcional, obstacularizando novas epistemes esportivas cujos propósitos é tomar a questão da "diferença" como índice de conhecimento das (e sobre as) práticas esportivas. Não obstante, e na prática, a FIFA atua quase como se fosse mais um EstadoNação, cujos interesses se impõem no concerto dos países submetidos às regras de execução dos megaeventos por ela patrocinados.

O espraiamento de outras formas de violência política, sobretudo essas que gravitam em torno dos "criativos" enfrentamentos de gênero que, certamente, se expandem em profusão na atualidade (mas que apenas uma fração acaba alcançando as redes sociais) seguem, ao menos desde a Copa do Brasil, minimizados pela entidade. 0 problema, no entanto, é que obviamente isso tem a ver com o modo como a própria FIFA induz e reafirma a sociabilidade heteronormativa no propalado bordão generalista de que uma Copa seria o 
exercício do "congraçamento entre povos", numa concepção conservadora, portanto excludente, de política esportiva.

Entendemos por enfrentamentos de gênero não somente concepções que partem de posicionamentos pessoais ou em causa da pessoa, mas também muitas das ondas de opinião pública que, inclusive, alimentam debates ideológicos mais amplos, tais como, por exemplo, a generificação da campanha presidencial brasileira em 2018. Nesta ocasião, foram notórios como os enfrentamentos de gênero se colocaram francamente não apenas como estratégias de marketing político, mas também como projetos de "Brasis" em confronto. Nas eleições de 2018, as questões de gênero pautaram grande parte das controvérsias entrecruzadas às questões morais, sexuais e religiosas. ${ }^{13}$

Nesse sentido, interessante a obsessão desses rapazes que protagonizaram o aludido caso com tal (hetero)sexualidade. Não resolve apenas agrupá-los, talvez, sob a fatura de "sexistas, machistas e misóginos" ou expiá-los em condenações formais, vindas da FIFA ou de uma mídia indignada. Há algo enigmático na latente sexualização dos corpos e de suas línguas. Sexualiza-se o outro para justificar um estereótipo e legitimar um desejo auto-imputado. Verbaliza-se (sobre) o sexo a fim de escamotear a má compreensão que se tem da amplitude do mesmo. No fim das contas, só a heteronormatividade instituída rege incólume: pênis encontram vaginas dentro de regras (binárias e fixas) instituídas. No futebol e nos esportes a exceção é torta, aberrante: lésbicas, gays, bissexuais, pessoas transgênero, orgias sexuais e/com travestis não existem - e na visão de muitos, nunca existirão no rincão masculinista do esporte bretão. Aos aberrantes, a invisibilidade - ou a inexistência, em se tratando do evento no quintal de Vladmir Putin.

\footnotetext{
${ }^{13}$ Tais questões produziram vários polos nevrálgicos, entre eles muitos motivados pelas posições do então candidato Jair Bolsonaro, que em seu histórico parlamentar protagonizou vários episódios em que manifestou uma inconteste misoginia, desembocando em manifestações multipolarizadas nas eleições e contrárias à sua candidatura, denominadas de "\#Ele Não". Para uma visão estatística geral dos votos repartidos segundo o binarismo homem e mulher nessas eleições consultar, por exemplo, <http://bit.ly/2Cwj0jY>. Porém, as questões de gênero também se expandiram para o campo LGBTI+ (de lésbicas gays, bissexuais, travestis, transgêneros, intersexos e demais), produzindo continuadas e acaloradas controvérsias, protagonizando episódios de violência e intimidação generalizados que estiveram no epicentro dos resultados eleitorais. Consultar na mídia, por exemplo, <http://bit.ly/2CvABYY>.
} 
Tanto a "boceta rosa" quanto o "dar para o Neymar", frases utilizadas na abordagem dos torcedores em relação à mulher russa, fazem referências a dois órgãos sexuais que institucionalizam o sexo no corpo. Vagina e ânus são dois lugares que o simbolismo comum remete ao prazer e à repugnação, respectivamente. Não se considera (ou tolera) a inversão desta simbologia. Ora, vagina e ânus são órgãos, igualmente, excretores. E ambos podem ser canais de prazer para a entrada de pênis, dildos ou dedos, dependendo de que perspectiva sexual sejam tratados.

No entanto, numa arquitetura heteronormativa construída, há apenas algumas topografias aceitas e permitidas. A região da vulva (envoltório da vagina) é a única zona produtora de prazer legitimada e aceita tacitamente. Excetuando-se os momentos em que é fetichizado nos corpos de mulheres ou travestis por machosalfa, o ânus/cu é terminantemente excluído desta geografia e colocado sob o signo da injúria. Como já foi sublinhado, “[...] ser penetrado é algo indesejável, um castigo, uma tortura, um ato odioso, uma humilhação, algo doloroso, a perda da masculinidade, algo em que jamais se poderia encontrar prazer". ${ }^{14}$

Porém, em que pese a vagina estar elevada a órgão máximo vangloriado pelos machos heterossexuais brasileiros nos bastidores da Copa da Rússia, o cu (e por extensão as nádegas, bunda e seu envoltório) é o órgão que exerce um fascínio hipnótico em seus discursos. Não da mesma monta, nem no mesmo sentido, mas sob uma pragmática histérica. "Homem que é homem não se deixa tocar no traseiro", provavelmente é um mantra seguido por tais sujeitos. Em suas lógicas, homem que é homem, aliás, não deixa o amigo se aproximar muito dessa área, mesmo num encontrão do futebol de várzea do fim de semana. Homem macho-alfa penetra "bocetas rosas" e nunca deixa ser penetrado, principalmente por Neymares da vida. ${ }^{15}$

\footnotetext{
${ }^{14}$ SÁEZ; CARRASCOSA. Por el culo, p. 9. (Tradução livre).

${ }^{15} \mathrm{Em}$ um texto datado, porém interessante, DAMATTA (1997) se refere à brincadeira do "tem pente aí?", muito comum nos idos dos anos 1970-80 entre garotos adolescentes em idade escolar que, inadvertidamente, tocavam o amigo na região das nádegas requisitando o objeto para pentear os cabelos. O toque era um código, partícipe de um universo extremamente machista, que feminilizava o sujeito tocado e postulava o lugar em que a masculinidade (dominante) deveria estar (de quem tocava).
} 
Nesse regime cultural heterocentrado, a mulher é quem deve ser penetrada por excelência, pois é tida como inferior, alguém não respeitado em seus desejos sexuais - tanto é assim, que uma "mulher ativa" sexualmente é, em geral, mal vista, pois lhe é negada sua agência sexual. Corpos de mulheres são os únicos legitimamente penetráveis (via "bocetas") no imaginário coletivo de homens e o ânus é excluído do espaço social, com a consequente prática de sexo anal atrelada ao status de tabu.

O interessante no xingamento relativo ao ânus/cu é que as problemáticas de gênero se postulam a partir da regulação deste órgão como um espaço político, que regula a masculinidade heterocentrada e machista. ${ }^{16}$ Para os autores, o que define tal masculinidade não são os genitais, tampouco os hormônios masculinos, mas a ostensiva impenetrabilidade do cu. Lembrando o "terror anal",17 enquanto a subjetividade masculina heterossexual assenta-se no paradigma do corpo cuja boca está sempre se abrindo em público e o ânus segue cuidadosamente fechado, a subjetividade feminina heterossexual opera no contrário: privatização da boca e abertura pública do ânus e da vagina.

\section{ALGUMAS NOTAS CONCLUSIVAS SOBRE MISOGINIA E SEUS DERIVADOS}

O futebol como prática hegemônica disseminada globalmente, que insiste em existir nas expressões políticas, estéticas e sensoriais de valências simbólicas múltiplas de indivíduos e grupos, legitima as mais diversas formas de sociabilidade

na contemporaneidade. É o que se pôde constatar neste episódio, aqui descrito e analisado, ocorrido na Copa da Rússia em 2018.

Tais discursos sobre gênero e sexualidade, ${ }^{18}$ por assim dizer, acabam trazendo, no fundo, "modos de existência", que habitam o universo do futebol e se materializam e espraiam em "múltiplos futebóis", os quais atingem expressões politizadas e que podem ser exploradas inside out (de dentro) deste fenômeno global. E é interessante pensar nas práticas que tensionam, de modo permanente,

\footnotetext{
${ }^{16}$ SÁEZ; CARRASCOSA. Por el culo, 2011.

${ }^{17}$ PRECIADO. Terror Anal, 2009.

${ }^{18}$ BUTLER. Problemas de gênero, 2003.
} 
tal futebol hegemônico: o qual ao tentar manter seu status quo por meio de competições intercontinentais (e imensa capilarização em rede de espetáculos locais), faz transbordar formas dissonantes que legitimam tais práticas.

O caso dos torcedores brasileiros e da jovem russa não cessa de produzir desdobramentos funestos também no interior da própria cultura misógina russa, expondo as chagas do conservadorismo político e comportamental de um país que ainda mal digeriu o seu ocaso como superpotência da Guerra Fria. Grupos extremistas nacionalistas condenaram a garota porque ela teria submetido a virilidade russa (e a "verdadeira" mulher eslava) aos caprichos de estrangeiros ruidosos, festivos e, no limite, inferiores. E nesse misto de interpretações cruzadas em que concepções de nação e de gênero se misturam num moralismo perverso, o futebol-espetáculo vai mais do que se desdobrando como um lugar fértil onde vicejam os identitarismos - até mesmo porque ele ainda ostenta um lugar de centralidade nas expressões esportivas, oferecendo o contraponto "canônico", por meio do qual outras formas de apropriação do jogo podem dialogar criticamente com seus pressupostos técnicos, estéticos, políticos e valorativos.

Partindo deste episódio, pudemos refletir sobre a sexualização de corpos no contexto futebolístico midiatizado, pensando o futebol (enquanto prática cultural) pela relativização de seus modos simbólicos de impor regras e sociabilidades esportivas, tomadas tacitamente como universais. Quisemos dizer, outrossim, que o problema da multiplicidade ou das perspectivas de apropriação dos futebóis dentro do Futebol é (e sempre foi) inerente à sua prática, quer amadora (lúdica) ou espetacular (profissional), e visibilizar as múltiplas insurgências em seu interior seria perceber um movimento de dentro, que se projeta intensamente a partir de novos agentes, os quais ousam reivindicar a prática como índice de empoderamento, de novos identitarismos, do/no futebol e nos esportes. 


\section{REFERÊNCIAS}

ARCHETTI, Eduardo. Masculinidades - fútbol, tango y polo en la Argentina. Buenos Aires, Editorial Antropofagia, 2003.

BUTLER, Judith. Problemas de gênero: feminismo e subversão da identidade. Rio de Janeiro: Editora Civilização Brasileira, 2003.

CAMARGO, Wagner Xavier de. A Champions LiGay e a colonização do futebol. São Paulo, Ludopédio, v. 113, n. 12 , 2018, p. 1-6.

COSTA, Carlos Eduardo. Inkidene Hekugu - uma etnografia da luta e dos lutadores no Alto Xingu. (Tese de Doutorado). PPGAS-UFSCar, São Carlos 2013.

DAMATTA, Roberto. "Tem pente aí? reflexões sobre a identidade masculina". In: CALDAS, Dario. Homens. São Paulo: SENAC, 1997, p. 31-49.

DUGGAN, Lisa; HUNTER, Nan D. Contextualizing the Sexuality Debate: a chronology 1966-2005. In: Sex Wars: sexual dissident and political culture. New York/London: Routledge/Taylor and Francis Group, 2006, p. 15-28.

ELIAS, Norbert. Em busca da excitação. Lisboa: Difel, 1992.

OLÉCIO, Reinaldo. A sociabilidade esportiva das igrejas Renascer em Cristo e Bola de Neve. Luiz Henrique de Toledo \& Carlos Eduardo Costa (orgs). Visão de jogo: antropologia das práticas esportivas. São Paulo: Terceiro Nome, 2009.

POTECHI, Bruna. Fazer mulher, fazer lei: uma etnografia da produção de leis no Congresso Nacional Brasileiro. (Tese de Doutorado). PPGAS-UFSCar, São Carlos 2018.

PRECIADO, Paul B. Terror Anal. Apuntes sobre los primeros días de la revolución sexual. IN: HOCQUENGUEM, Guy. El deseo homosexual. Espanha: Editora Melusina, 2009, p. 133-174.

$\mathrm{RICH}$, Adrienne. La heterosexualidad obligatoria y la existencia lesbiana. In: NAVARRO, M.; STIMPSON, C. R. (eds.) Sexualidad, género y roles sexuales. México: Fondo de Cultura Económica, 1999, p. 159-211.

SÁEZ, Javier; CARRASCOSA, Sejo. Por el culo: políticas anales. Barcelona: Ed Triangulín, 2011.

TOLEDO, Luiz Henrique. Vaias, xingamentos e apupos: nacionalismo esportivo à flor da pele. Cuadernos del Mundial. Brasil 2014. CLACSO. Disponível em: https://www.clacso.org.ar/cuadernosdelmundial/opinion16.php. Acesso em: 03 dez 2018.

WAGNER, Roy. Símbolos que representam a si mesmos. São Paulo: Editora Unesp, 2017. 